\title{
Effect of ventromedial hypothalamic lesions on schedule-induced polydipsia
}

\author{
PAUL J. KULKOSKY, KAREN E. MOE, STEPHEN C. WOODS, and ANTHONY L. RILEY \\ University of Washington, Seattle, Washington 98195
}

\begin{abstract}
Rats with bilateral electrolytic lesions of the ventromedial hypothalamus were maintained at either $80 \%$ of their preoperative lean weights or $80 \%$ of their postoperative obese weights. Unlike sham-operated rats maintained at $80 \%$ of their weights, neither group of lesioned rats acquired schedule-induced polydipsia after 15 daily 1 -h sessions on a free variable-interval 1 -min food schedule with water continuously available. The results are consistent with previous findings of reduced drinking responses of ventromedially lesioned rats to a variety of conditions which increase drinking in normal rats.
\end{abstract}

Falk $(1961,1969)$ demonstrated that, if water is made continuously available to food-deprived rats receiving pellets on an intermittent schedule, the rats drink large quantities of water during the experimental session. Typically, this drinking, known as schedule-induced polydipsia (SIP), occurs immediately following the delivery of a food pellet. Although this phenomenon has been variously interpreted, a number of investigators (Bond, 1973; Hawkins, Schrot, Githens, \& Everett, 1972; Keehn, 1972; Lotter, Woods, \& Vasselli, 1973; Reynierse, 1966; Stein, 1964) have suggested that this postpellet drinking is elicited by the completion of a meal and therefore functionally similar to prandial drinking.

Although a number of researchers have demonstrated effects of central nervous system lesions on SIP [e.g., Falk (1964) reported attenuation of SIP following lateral hypothalamic lesions and Wayner and Greenberg (1972) reported enhancement of SIP following septal lesions], there has as yet been no clear demonstration of the effects of ventromedial hvpothalamic lesions. Falk (1964) described impaired lick efficiency but continued drinking in rats given ventromedial hypothalamic lesions 1 day prior to testing, but no data were presented. Since electrolytic lesions or knife cuts of the ventromedial hypothalamic area have been reported to cause reduced water/food intake ratios [Stevenson (1949, 1969); Stevenson, Welt, \& Orloff (1950)] and reduced drinking responses to food or water deprivation, osmotic load or hypovolemia (Sclafani, Berner, \& Maul, 1973; Smith, Salisbury, \& Weinberg, 1961), it is conceivable that they would also adversely affect SIP. The purpose of the present study was to examine the effects of ventromedial hypothalamic lesions on the acquisition of SIP.

This research was supported by National Institutes of Health This research was to S. C. Woods and National Science Grant No. AM-17112 to S. C. Woods and Nation Grant No. GB-40314 to R. C. Bolles. We thank R. H. Lovely and $M$. H. Smith for their helpful comments and Shirley Paton and Grace Hofman for their technical assistance. Requests for reprints should be addressed to Paul J. Kulkosky, Requests for reprostogitogy NI-25, University of Washington, Seattle, Washington 98195. A. L. Riley is presently at the Department of Psy chology, Dalhousie University, Halifax, Nova Scotia, Canada.
Recently, a number of studies of appetitive and motivational deficits consequent to ventromedial hypothalamic lesions have stressed that obese lesioned rats maintained at $80 \%$ of their obese weights perform more poorly than lesioned rats maintained at $80 \%$ of their preoperative lean weights on a variety of operant tasks (e.g., Kent \& Peters, 1973; Marks \& Remley, 1972; Peters, Sensenig, \& Reich, 1973; Porter \& Allen, 1972; Sclafani \& Kluge, 1974). Therefore, the present experiment included groups of lesioned rats at both weight levels.

\section{METHOD}

\section{Subjects}

Subjects were 12 experimentally naive male Long-Evans rats, approximately 100 days old at the time of surgery. They were individually housed in stainless steel cages and had access to ad-lib Purina Rat Chow and water unless otherwise specified.

\section{Surgery}

Subjects were anesthetized with Halothane and placed in a stereotaxic apparatus. Bilateral electrolytic lesions were made by passing $2 \mathrm{~mA}$ of direct anodal current for $20 \mathrm{sec}$ between a stainless steel electrode insulated except for $.5 \mathrm{~mm}$ at the tip and a cathode connected to an ear bar, with the electrode aimed at the following coordinates (Pellegrino \& Cushman, 1967): AP $+5.8 \mathrm{~mm}, \mathrm{~L} \pm .75 \mathrm{~mm}$, DV $-3.25 \mathrm{~mm}$. In four sham-operated controls, the electrode was not lowered below the skull. Controls and four obese lesioned rats were maintained for 70 days with ad-lib food and water prior to the onset of the experiment. Four lesioned rats were allowed 2 weeks to recover with restricted food prior to being reduced to $80 \%$ of their preoperative weights.

\section{Apparatus}

Three Scientific Prototype experimental chambers were used during the polydipsia sessions. A $5 \times 5-\mathrm{cm}$ brass food hopper was located on the front wall $2 \mathrm{~cm}$ above the grid floor and $4 \mathrm{~cm}$ from the left side wall. A graduated drinking tube was located on the left side wall. Its spout protruded $2 \mathrm{~cm}$ into the chamber at a point $4 \mathrm{~cm}$ above the floor and $8 \mathrm{~cm}$ from the front wall. Electromechanical relay equipment controlled the presentation of $45-\mathrm{mg}$ Noyes pellets.

\section{Procedure}

Following either the 70-day maintenance period or the 2-week 


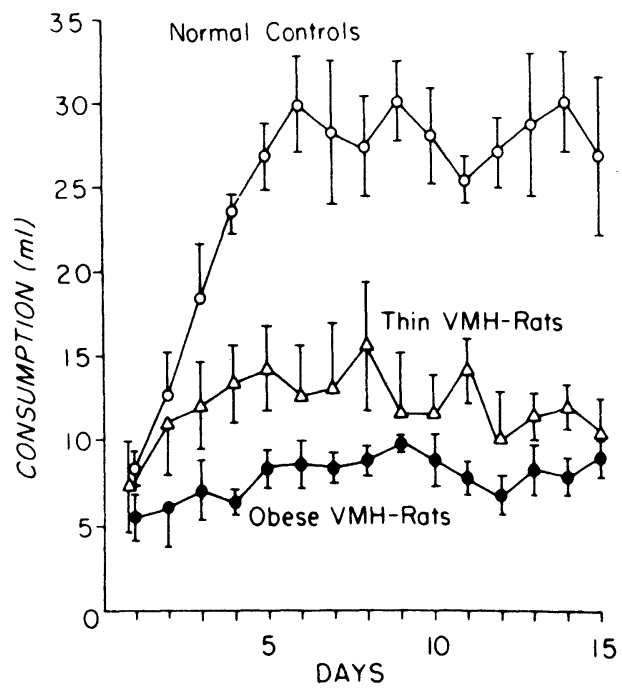

Figure 1. Mean water consumption (in milliliters) by the three groups of rats on Days 1-15. Lines represent one standard error of the means.

recovery period, all rats were deprived of food but given continued ad-lib access to water. When subjects had been reduced to $80 \%$ of their postoperative weights (lesioned obese mean $=556.8 \mathrm{~g} ;$ sham-operated mean $=345.3 \mathrm{~g}$ ) or $80 \%$ of their preoperative weights (lesioned lean mean $=328.8 \mathrm{~g}$ ), they were placed in the experimental chambers for daily 1-h sessions. Food pellets were presented independently of each rat's behavior on a variable-interval 1-min schedule. Water was continuously available during this session. The total food and water consumption during the hour were recorded. This procedure was continued for 15 days.

\section{Histology}

At the conclusion of the experiment, lesioned rats were sacrificed with an overdose of Equi-Thesin and perfused intracardially with isotonic saline followed by formalin. liorty-micron sections were subsequently prepared from the appropriate areas of the brains.

\section{RESULTS}

Water consumption data are summarized in Figure 1. Sham-operated rats drank approximately $8 \mathrm{ml}$ each on Day 1 , and their consumption gradually increased over sessions, reaching an average of around 25 to $30 \mathrm{ml} / \mathrm{session}$ on Days 5-15. Trend analysis revealed a highly significant sessions effect on water consumption for this group $(F=11.90, \mathrm{df}=14 / 42, \mathrm{p}<.005)$. Obese lesioned rats drank an average of $6 \mathrm{ml}$ on Day 1 . However, their consumption did not increase appreciably over sessions, such that their intake on Day 15 did not differ significantly from that of Day 1 $(\mathrm{t}=1.76, \mathrm{df}=3, \mathrm{p}>.05)$. Trend analysis revealed a nonsignificant sessions effect for these rats $(F=1.17$, $d i=14 / 42, p>0.5)$. Lean lesioned rats drank approximalely $7 \mathrm{ml}$ each on Day 1 . Their consumption also did not increase appreciably over sessions, such that their intake on Day 15 did not differ signilicantly from that of Day $1(\mathrm{t}=2.19, \mathrm{df}=3, \mathrm{p}>.05)$. Although trend analysis revealed a significant effect of sessions on water consumption for this group $(F=2.80, \mathrm{df}=14 / 42$, $\mathrm{p}<.01)$, neither the linear nor the quadratic components of this effect were significant. Mean water consumption of the sham-operated rats was significantly greater than that of the obese lesioned rats by Day 2 $(t=3.52, d f=6, p<.02)$ and remained so for all successive sessions. Mean water consumption by the sham-operated controls was significantly greater than that of the lean lesioned rats by Day $4(\mathrm{t}=3.07, \mathrm{df}=6$, $p<.05)$ and remained so for all successive sessions. Mean water consumption of the lean lesioned rats across all sessions was nonsignificantly greater than that of the obese lesioned rats $(F=4.58, \mathrm{df}=1 / 6, \mathrm{p}<.1)$. All rats ate all of the delivered pellets on each session.

Reconstructions of the largest and smallest lesions are presented in Figure 2. The lesions were reconstructed by tracing the damage to each brain onto drawings of sections through the rat brain taken from Pellegrino and Cushman (1967). The lesions were generally large, involving damage to most ventromedial hypothalamic structures medial to the fornices and ventral to the dorsomedial nuclei and extending from a position just rostral to the mammillary bodies to just caudal to the optic chiasma.
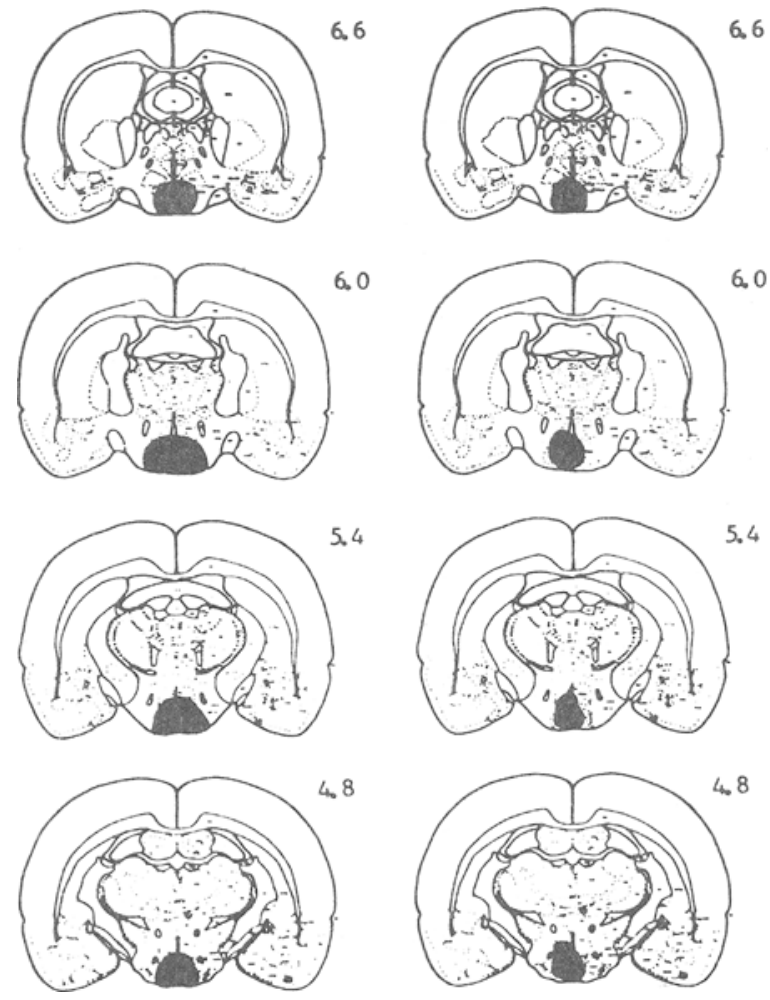

Figure 2. Reconstructions of the largest (left) and smallest (right) lesions. The numbers represent anterior distance from the interaural line in millimeters. 


\section{DISCUSSION}

The pattern of acquisition of SIP of the sham-operated rats was similar to that reported previously for this schedule (Reynierse \& Spanier, 1968). The lesioned rats, however, did not drink reliably more water on Session 15 than they had on Session 1. Over the last five sessions, the sham-operated rats had a very consistent pattern of postpellet drinking throughout each session. However, the obese lesioned rats demonstrated a more irregular drinking pattern, with drinking often ceasing altogether toward the end of the session. Lean lesioned rats also had an irregular drinking pattern, one which was often followed or replaced by vigorous sniffing, gnawing, and clawing of the food hopper.

Earlier studies indicate that ventromedially lesioned animals have hypodipsia (Andersson \& McCann, 1955, 1956), a reduced water/food intake ratio (Stevenson, 1949, 1969; Stevenson, Welt, \& Orloff, 1950) and reduced drinking responses to depivation or physiological challenge (Sclafani, Berner, \& Maul, 1973; Smith, Salisbury, \& Weinberg, 1961). The present results show that ventromedially lesioned rats have a comparable deficit for drinking in a situation that produces exaggerated water intake in normal rats.

Although neither group of lesioned rats acquired SIP, the lean group typically drank more water than the obese group. This finding is in agreement with reports of generally poorer performance of obese lesioned rats compared to lean lesioned rats on a variety of operant tasks (Kent \& Peters, 1973; Marks \& Remley, 1972; Peters, Sensenig, \& Reich, 1973; Porter \& Allen, 1972; Sclafani \& Kluge, 1974).

\section{REFERENCES}

Andersson, B., \& McCann, S. M. Hypothalamic control of water intake. Journal of Physiology, 1955, 129, 44.

Andersson, B., \& McCann, S. M. The effect of hypothalamic lesions on the water intake of the dog. Acta Physiologica Scandinavica, 1956, 35, 312-320.

Bond, N. W. Schedule-induced polydipsia as a function of the consummatory rate. Psychological Record, 1973, 23, 377-382.

Falk, J. L. Production of polydipsia in normal rats by an intermittent food schedule. Science, 1961, 133, 195-196.

Falk, J. L. Studies on schedule-induced polydipsia. In M. J. Wayner (Ed.), Thirst: First international symposium on thirst in the regulation of body weight. New York: Pergamon Press, 1964. Pp. 95-116.
Falk, J. L. Conditions producing psychogenic polydipsia in animals. Annals of the New York Academy of Sciences, 1969, 157, 569-593.

Hawkins, T. D., Schrot, J. F., Githens, S. H., \& Everett, P. B. Schedule-induced poly dipsia: An analysis of water and alcohol ingestion. In R. M. Gilbert and J. D. Keehn (Eds.), Schedule effects: Drugs, drinking, and aggression. Toronto: University of Toronto Press, 1972. Pp. 95-128.

Keehn, J. D. Schedule-dependence, schedule-induction, and the law of effect. In R. M. Gilbert and J. D. Keehn (Eds.), Schedule effects: Drugs, drinking, and aggression. Toronto: University of Toronto Press, 1972. Pp. 65-94.

Kent, M. A. \& Peters, R. H. Effects of ventromedial hypothalamic lesions on hunger-motivated behavior in rats. Journal of Comparative and Physiological Psychology, 1973, 83, 92-97.

Lotter, E. C., Woods, S. C., \& Vasselli, J. R. Schedule-induced polydipsia: An artifact. Journal of Comparative and Physiological Psychology, 1973, 83, 478-484

Marks, H. E., \& Remley, N. R. The effects of type of lesion and percent body weight loss on measures of motivated behavior in rats with hypothalamic lesions. Behavioral Biology, 1972, 7, 95-111.

Pellegrino, L. J., \& Cushman, A. J. A stereotaxic atlas of the rat brain. New York: Appleton-Century -Crofts, 1967.

Peters, R. H., Sensenig, L. D., \& Reich, M. J. Fixed-ratio performance following ventromedial hypothalamic lesions in rats. Physiological Psychology, 1973, 1, 136-138.

Porter, J. H., \& Allen, J. D. Food-motivated performance as a function of weight loss in hypothalamic hyperphagic rats. Psy chonomic Science, 1972, 28, 285-288.

Reynierse, J. H. Excessive drinking in rats as a function of number of meals. Canadian Journal of Psychology, 1966, 20 82-86.

Reynierse, J. H., \& Spanier, D. Excessive drinking in rats' adaptation to the schedule of feeding. Psychonomic Science, $1968,10,95-96$.

Sclafani, A. Berner, C. N., \& Maul, G. Feeding and drinking pathways between medial and lateral hypothalamus in the rat. Journal of Comparative and Physiological Psychology, 1973, 85, 29-51.

Sclafani, A., \& Kluge, L. Food motivation and body weight levels in hypothalamic hyperphagic rats: A dual lipostat model of hunger and appetite. Journal of Comparative and Physiological Psychology, 1974, 86, 28-46.

Smith, M. H., Salisbury, R., \& Weinberg, H. The reaction of hypothalamic hyperphagic rats to stomach preloads. Journal of Comparative and Physiological Psychology, 1961, 54, G60-fik4

Stein, L. Excessive drinking in the rat: Superstition or thirst? Journal of Comparative and Physiological Psychology, 1964, 58, 237-242.

Stevenson, J. A. F. Effects of hypothalamic lesions on water and energy metabolism in the rat. Recent Progress in Hormone Research, 1949, 4, 363-394.

Stevenson, J. A. F. Neural control of food and water intake. In W. Haymaker, E. Anderson, and W. J. H. Nauta (Eds.), The hypothalamus. Springfield: Thomas, 1969.

Stevenson, J, A F Welt, L G \& Orloff, J Abnormalities of water and electroly te metabolism in rats with hypothalamic lesions. American Journal of Physiology, 1950, 161, 35-39.

Wayner, M. J., \& Greenberg, I. Effects of septal lesions on palatability modulation of schedule-induced polydipsia. Physiology and Behavior, 1972, 9, 663-665.

(Received for publication July 11,1974 ; revision received November $25,1974$. 